\title{
Plasma Brain Derived Neurotrophic Factor Level and Its Gene Polymorphism in Toxic Suicidal Behavior
}

\author{
Mohammad A. El-Kattan ${ }^{1}$, Ahmed M.N.Z. Helaly ${ }^{1}$, Zakaria F. Lotfy ${ }^{2}$, \\ Adel M. El-Mansoury ${ }^{1}$, Samia A. Hassan ${ }^{1}$
}

\begin{tabular}{|c|c|}
\hline & ABSTRACT \\
\hline $\begin{array}{l}\text { KEYWORDS } \\
\text { BDNF, } \\
\text { Polymorphism, } \\
\text { Suicide, } \\
\text { Genetics. }\end{array}$ & $\begin{array}{l}\text { Suicide represents a major health problem, it is suggested that multiple factors } \\
\text { influence the rate of suicide. Brain derived neurotrophic factor (BDNF) is considered a } \\
\text { reliable biological marker of suicide. Its level decreases in all suicidal victims whether } \\
\text { or not they are suffering from psychiatric troubles. The objective of this work was to } \\
\text { compare BDNF levels and single nucleotide polymorphism in suicidal and non-suicidal } \\
\text { groups to explore whether suicide is related to BDNF related mechanisms. Plasma } \\
\text { BDNF levels were screened in conjunction with tracking of the } 196 \mathrm{G} \text { / } \text { (val66met, } \\
\text { rs6265) polymorphism in } 89 \text { suicidal patients that visited the toxicology unit and } 89 \\
\text { control. The pattern of gene polymorphism did not show significant differences } \\
\text { between suicidal patients and control. However, the plasma BDNF levels were higher in } \\
\text { suicidal cases. It can be concluded that the combined assessment of BDNF showed no } \\
\text { difference in genotyping between suicide and control groups. However, higher levels of } \\
\text { plasma BDNF were detected in the samples taken from suicide attempters. }\end{array}$ \\
\hline
\end{tabular}

\section{Introduction}

Suicidal behavior (SB) is considered a major health challenge. According to WHO studies, up to $2 \%$ of the deaths in the world are caused by unfortunate successful suicidal attempts that represent the $10^{\text {th }}$ leading cause of death in the world. It is expected that 1.5 million will die as a result of suicide in the next 10 years all over the world (WHO, 2002). Multifactorial causes are likely to influence the tendency to suicide for example biological, genetic and psychosocial factors (Hawton and Van Heeringen, 2009).

Neurotrophins are responsible for regulation of structural, synaptic, and

\footnotetext{
(1) Forensic Medicine \& Clinical Toxicology Department, Mansoura Faculty of Medicine, Egypt.

(2) Clinical Pathology Department, Mansoura Faculty of Medicine, Egypt.
}

morphological plasticity of the central nervous system. Furthermore, they support the function and response of the synaptic connections and neurotransmission. Brain derived neurotrophic factor is one of the most important extensively studied brain growth factors. It is the ligand binding to a tropomyosin-related kinase $\mathrm{B}$ (TrkB) receptor and is considered a reliable biological marker of suicide. Its level decreases in all suicidal victims whether or not they are suffering from predisposing psychiatric troubles (Paska et al., 2013).

A low level of BDNF is associated with serotonergic abnormalities in young suicidal patients corresponding to possible defective brain development. It is worthy to say that serotonin dysfunction is a cornerstone factor in the pathogenesis of anxiety and depression (Dwivedi, 2012).

It is hypothesized that poor blood BDNF level is associated with poor neurogenesis in 
the hippocampus that explains the tendency to commit suicide. Many studies are supporting that stress as well as decreased BDNF level affects neuronal plasticity as well as neurogenesis (Van Heeringen et al., 2011).

The most extensive research had been done on a single-nucleotide polymorphism (SNP) (rs6265) in coding region of exon $\mathrm{V}$ of the BDNF gene, producing an amino acid substitution (valine to methionine) at codon 66 (Val66Met). This amino acid substitution corresponds to abnormal intracellular recruitment of BDNF. As a result, the production of the functional neurotrophin is reduced in the central nervous system (Czira et al., 2012).

The average serum levels of BDNF are above 100-fold higher than plasma levels. This result can be explained by degranulation of platelets in the process of clotting. Clinical studies reported that circulating plasma BDNF is considered a good biomarker for depression and suicide (Brunoni et al., 2008; Piccinni et al., 2008). It is important to add that BDNF originates from both neurons and astrocytes, passes the blood brain barrier using an active transport mechanism and plasma BDNF levels strongly correlate with cortical gene expression (Lang et al., 2007).

The aim of this work was to study the BDNF gene polymorphism in relation suicide and to check plasma levels of BDNF in the suicidal group. The combined parameters are expected to explain the role of BDNF in suicide.

\section{Subjects and Methods}

\section{Subjects:}

This is a case control study that was conducted from April 2015 to March 2016. The patients were recruited from the Toxicology Unit, Mansoura Emergency Hospital, Dakahleia Governorate, Egypt.
Subjects were divided into two groups: 89 suicidal cases and 89 controls of both sexes. The age range of the suicidal patients was from 15-60 years. The suicidal cases with or without psychiatric history were included. Smokers, drug abusers and patients taking antidepressant drugs were excluded. The control samples were taken from the same locality with exposure to the same variables like time at which the blood samples were taken, storage, psychosocial standard, age, sex, smoking habits, nutritional status or alcohol intake. They were living in the same geographic area and had the same ethnicity as patients. They had no clinical evidence or family history of suicidal attacks. The blood samples were collected, plasma were separated and kept frozen at $-80{ }^{\circ} \mathrm{C}$ until the time of analysis.

The study was approved by the Research Ethics Committee (REC) for experimental and clinical studies at the Faculty of Medicine, Mansoura University, Egypt. Informed written consents were obtained from all subjects before starting the study. The study was performed according to the Declaration of Helsinki Principles.

\section{Methods:}

All studied subjects were subjected to the following:

1) Detailed history taking including a standardized questionnaire that was applied to confirm the actual suicidal behavior.

2) Blood sampling for estimation of plasma BDNF levels:

- Samples collection:

Venous blood samples $(2.5 \mathrm{ml})$ from patients and controls were obtained, preserved in ethylene diamine tetra acetic acid (EDTA) tubes and centrifuged at 4000 r.p.m for $15 \mathrm{~min}$. The samples were taken 30 minutes after the patients of self-deliberate poisoning were 
admitted to the Toxicology unit. The patient generally reached the hospital within the 1st to 6th hours after exposure to the acute poisoning.

- Samples storage:

Plasma components were stored at -80

${ }^{\circ} \mathrm{C}$ until the time of assay.

- Samples analysis:

Brain derived neurotrophic factor levels were evaluated in both patients and controls by an ELISA method (Human BDNF Eliza kit, Sun Red Biotechnology, Shanghai). The BDNF protein was expressed as equivalent of the human recombinant protein; the normal range of plasma BDNF was 0.1-10 $\mathrm{ng} / \mathrm{ml}$.

\section{3) Blood sampling for genotyping:}

Two and half (2.5) $\mathrm{ml}$ venous blood samples on EDTA containing tubes were collected from each subjects and left frozen at $-80{ }^{\circ} \mathrm{C}$ until applying the genotype test for presence or absence of SNP: 196 G/A (val66met, rs6265).

A commercial DNA extract kit, Gene Jet Whole Blood Genomic DNA purification Mini kit (Thermo Scientific, (EU) Lithuania) was applied to extract DNA from blood leukocytes. Typing of the BDNF 196 G/A (rs6265) gene polymorphism was done according to Choo et al.; (2014). The primer sequences (Biosearch technologies, USA) used were as follows: the forward primer 5'- GAG GCT TGA CAT TGG CT-3' and the reverse primer 5'-CGT GTA CAA GTC TGC GTC CT -3'. The reaction mixture volume was $25 u \mathrm{~L}$ and included $5 u$ l of 100ng/ul DNA, $15.0 u \mathrm{~L}$ of DeamTaq Green Master mix (Fermentas, Germany, Lot No.39428), $0.5 u \mathrm{~L}$ of each primer and $4 u \mathrm{~L}$ of distilled water. PCR reaction conditions were done on a thermo-cycler PTC-100 (BioRad) to amplify the DNA for 35 cycles. After 10 minutes heating at $95^{\circ} \mathrm{C}$, the cycle was divided into 30 seconds at $94^{\circ} \mathrm{C}, 30$ seconds at $62^{\circ} \mathrm{C}$, and 30 seconds at $72^{\circ} \mathrm{C}$, and finally 5 minutes heating at $72^{\circ} \mathrm{C}$. A total of $10 u \mathrm{~L}$ of the PCR products were resolved on $2 \%$ agarose gels to check the PCR products at the 113-bp fragment. RFLP analysis was done using FastDigest restriction enzyme NIaIII (Thermo Scientific, (EU) Lithuania) to cut the amplified DNA at the 196A site, and the product was evaluated by running electrophoresis in 3\% agarose gels and stained with ethidium bromide. Homozygous genotypes were discriminated by the presence of $113 \mathrm{bp}$ bands (G/G) or bands of 75,38 bp (A/A). The heterozygous genotype showed three bands: 113,75 , and 38 bp $(\mathrm{A} / \mathrm{G})$.

\section{Statistical analysis}

Statistical analysis of the data was performed using Excel (Microsoft Office 2013) and SPSS version 20 (SPSS, Inc., Chicago, IL, USA). Qualitative data were presented as number and percentage; X2 and Fisher's exact tests were used to compare groups. Quantitative data were presented as mean and S.D. or median and range. For comparison between the two groups, non-parametric Mann-Whitney and U-tests were used. Deviations from Hardy-Weinberg equilibrium expectations were determined using $\mathrm{X} 2$ test. Odds ratio (OR) and 95\% confidence interval (CI) were calculated. The correlations between different parameters were analyzed using Spearman's rank correlation coefficient. Changes in BDNF protein concentration and antibody titer over time were examined by Wilcoxon's paired signed-rank test. $\mathrm{P}$ value was considered significant if $<0.05$.

\section{Results}

The pattern of gene polymorphism did not show significant differences between suicidal patients and control. However, plasma BDNF levels were higher in suicidal cases (Table 1). The median of BDNF plasma levels 
was significantly higher in the suicide group with wider distribution in the control group (Figure 1). The median blood BDNF levels for AG and GG polymorphisms was 2.63 and 2.97 ng respectively in the suicide group while for the non-suicide group they showed a median of 2.32 and $1.99 \mathrm{ng}$ respectively (Table 2 ). The BDNF levels range from 0.02 to $11.64 \mathrm{ng}$ in suicidal AG genotype, and range from 1.89 to $13.51 \mathrm{ng}$ in suicidal GG genotype. The range of BDNF plasma levels in non-suicidal AG group was 1.29-18.6 ng. The range of BDNF in non- suicidal GG genotype was 0.88 to $15.5 \mathrm{ng}$ (Figure 2).

The pattern of gene polymorphism in both suicidal cases complaining of psychiatric diseases and those who committed suicide attempts with no history of psychiatric diseases was evaluated in table (3). The range of BDNF level in suicidal cases complaining of psychiatric troubles was 0.02 to $3.44 \mathrm{ng}$ and the range in suicidal cases not complaining of diseases was 1.76 to $13.51 \mathrm{ng}$ (Figure 3).

Table (1): Comparison of single nucleotide polymorphism between suicidal and non-suicidal groups in relation to brain derived neurotrophic factor (BDNF) plasma level $(n=178)$.

\begin{tabular}{|l|c|c|c|}
\hline \multicolumn{1}{|c|}{ Parameters } & Suicidal group (n=89) & $\begin{array}{c}\text { Non-suicidal group } \\
(\mathbf{n = 8 9 )}\end{array}$ & p value \\
\hline $\begin{array}{l}\text { BDNF level by ng/ml } \\
\text { described as median (Min-Max) }\end{array}$ & $2.72(0.02-3.51)$ & $2.11(0.88-18.6)$ & $\begin{array}{c}\mathrm{Z}=5.28, \\
\mathrm{p}<0.001^{*}\end{array}$ \\
\hline Single nucleotide polymorphism & $\mathrm{n}(\%)$ & $\mathrm{n}(\%)$ & \\
\hline AG $* *$ & $40(40)$ & $33(33)$ & $\begin{array}{c} \\
\text { GG }\end{array}$ \\
GG & $60(60)$ & $67(67)$ & 1.057, \\
\hline
\end{tabular}

n: number, ${ }^{* Z}$ : Mann Whitney test, $\chi 2$ : Chi square test, ${ }^{* *}$ The heterozygous genotype (A/G), homozygous genotype $(\mathrm{G} / \mathrm{G})$.

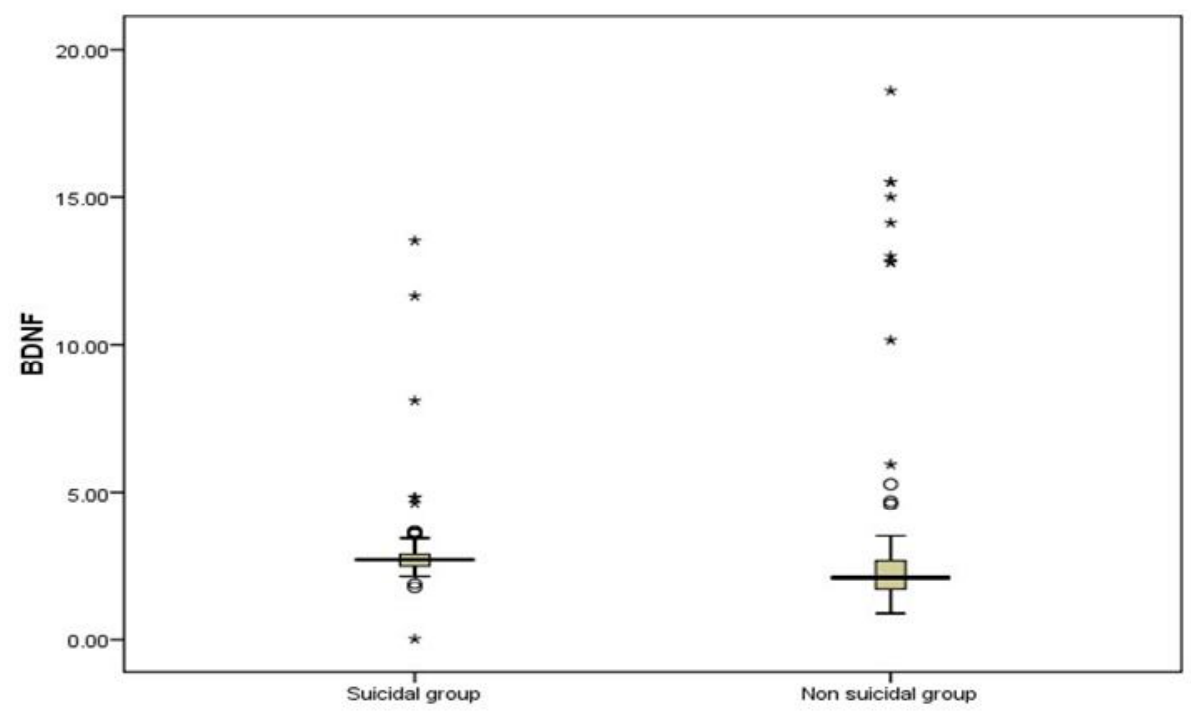

Fig.(1): The distribution of median plasma brain derived neurotrophic factor (BDNF) levels in both suicidal and nonsuicidal groups. 
Table (2): Comparison of single nucleotide polymorphism and median brain derived neurotrophic factor (BDNF) plasma level between suicidal and non-suicidal groups.

\begin{tabular}{|c|c|c|c|c|}
\hline $\begin{array}{c}\text { Gene } \\
\text { Polymorphism }\end{array}$ & $\begin{array}{c}\text { Suicidal group } \\
\mathbf{n = 8 9}\end{array}$ & $\begin{array}{c}\text { Non-suicidal group } \\
\mathbf{n = 8 9}\end{array}$ & $\begin{array}{c}\text { Mann } \\
\text { Whitney test }\end{array}$ & P value \\
\hline AG & $2.63(0.02-11.64)$ & $2.32(1.29-18.6)$ & $\mathrm{Z}=2.22$ & 0.026 \\
\hline $\mathrm{GG}$ & $2.97(1.89-13.51)$ & $1.99(0.88-15.5)$ & $\mathrm{Z}=4.99$ & $<0.001$ \\
\hline
\end{tabular}

n: number

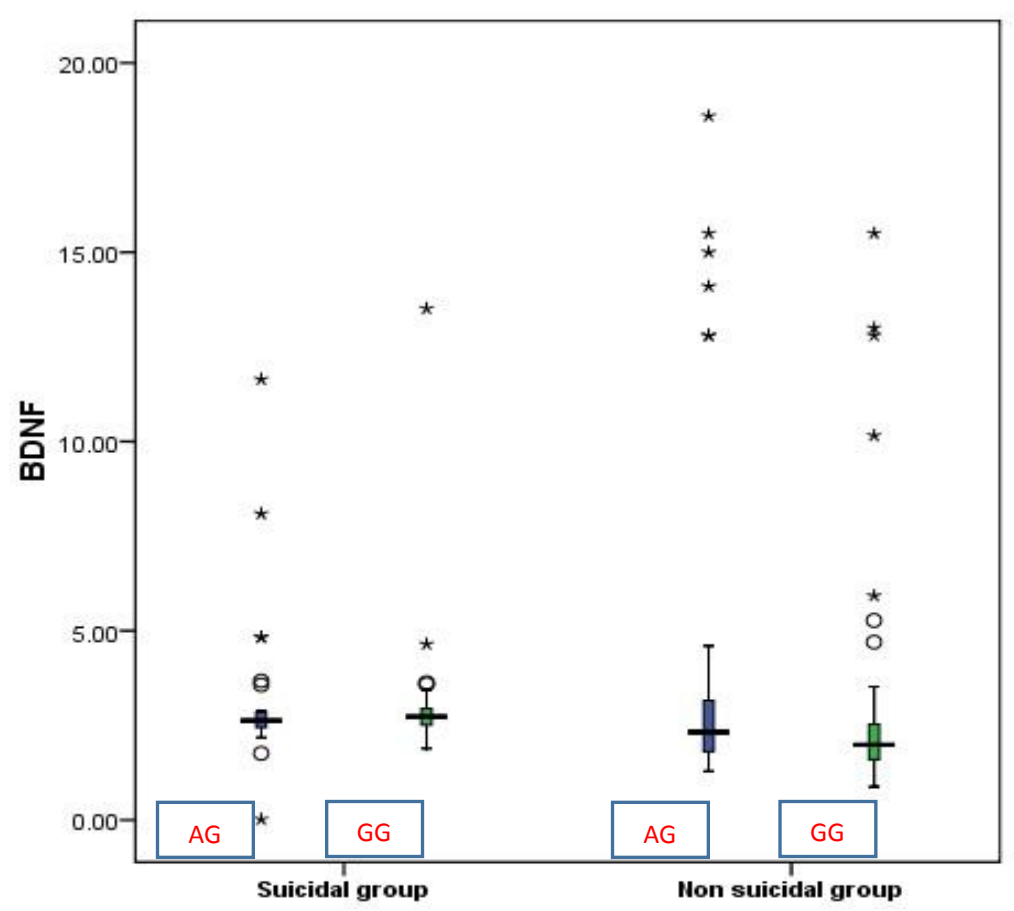

Fig.(2): Distribution of plasma levels of brain derived neurotrophic factor (BDNF) in suicidal versus nonsuicidal groups in both $\mathrm{AG}$ and GG phenotypes.

Table (3): Comparison between suicidal group complaining of psychiatric disease versus non psychiatric suicidal group regarding blood brain derived neurotrophic factor BDNF levels and gene polymorphism.

\begin{tabular}{|l|c|c|c|}
\hline \multirow{2}{*}{ Parameters } & \multicolumn{2}{|c|}{ Psychiatric diseases $(\mathrm{n}=89)$} & \multirow{2}{*}{$\mathrm{p}$ value } \\
\cline { 2 - 3 } & Present $(\mathrm{n}=18)$ & Absent $(\mathrm{n}=71)$ & \\
\hline BDNF & $2.59(0.02-3.44)$ & $2.73(1.76-13.51)$ & $\begin{array}{c}\mathrm{Z}=0.37, \\
\mathrm{p}=0.71\end{array}$ \\
\hline Gene polymorphism & $\mathrm{n}(\%)$ & $\mathrm{n}(\%)$ & \\
\hline AG & $7(40)$ & $29(40)$ & $\mathrm{p}=1$ \\
GG & $11(60)$ & $42(60)$ & \\
\hline
\end{tabular}

n: number 


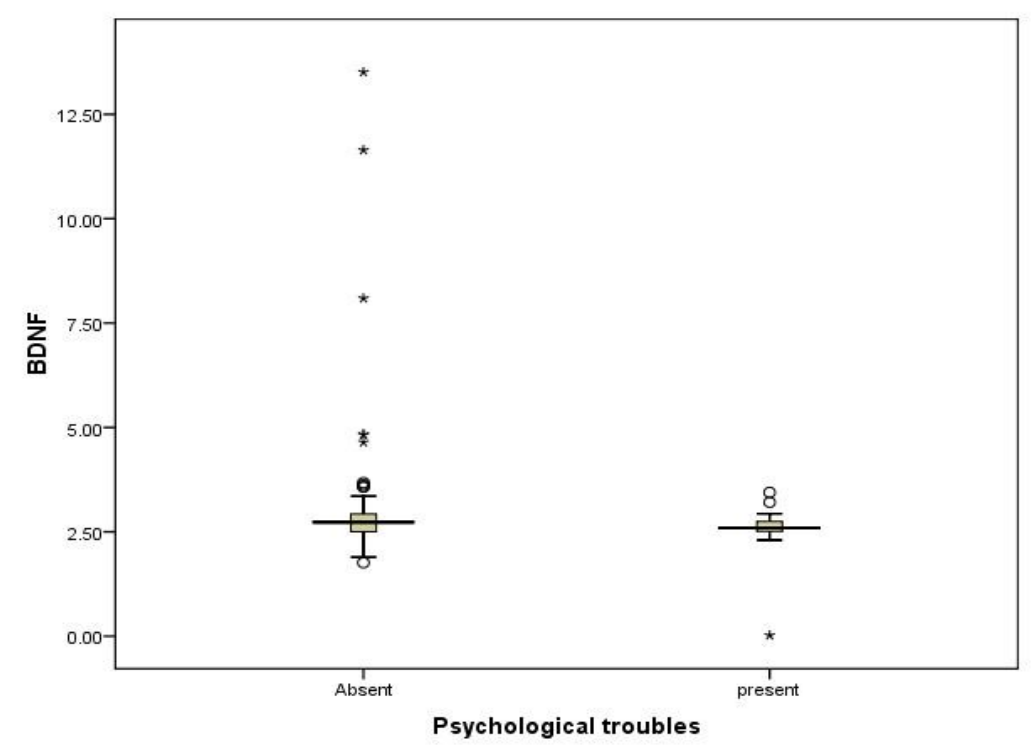

Fig.(3): The distribution of median brain derived neurotrophic factor (BDNF) plasma levels in suicidal cases with or without psychiatric diseases.

\section{Discussion}

The present study examined the comparison between gene expression of BDNF and BDNF gene polymorphism. Both results challenged genetic SNP and protein expression in relation to suicide. The BDNF blood level was higher in suicidal group in contrast to solid uniform genetic background of BDNF gene polymorphism. No statistically significant distribution of gene polymorphism was detected in relation to suicide.

On the other hand, screening of BDNF blood levels showed dynamic response in the suicidal group where the median BDNF blood level was higher in individuals attempting suicide than in control group, with wider distribution. At the same time, suicidal patients with psychiatric manifestation revealed lower blood levels of BDNF than those attempting suicide without history of psychiatric diseases. Still, both suicidal groups expressed higher plasma BDNF than the control.
Studies showed that BDNF is a strong marker for stress and suicide (Lang et al., 2007; Brunoni et al., 2008; Piccinni et al., 2008). Post mortem analysis of mRNA of BDNF extracted from hippocampus showed a significant reduction in hippocampal BDNF and TrkB mRNA expression among individuals who died by suicide compared to normal controls (Smith et al., 1995). The hypothesis tracking brain or blood levels of BDNF suggests that neuronal plasticity plays a role in the pathogenesis of suicide. Such proposed pathology is associated with modifications of BDNF expression (Dunman et al., 2000; Garcia, 2002; Fossati et al., 2004).

Brain derived neurotrophic factor is an important growth factor regulating the growth of serotonin secreting neurons and mediates neuronal plasticity supporting the nervous system and combating stress either acute or chronic. Furthermore, there were published data indicating that BDNF expression decreases in patients having psychiatric disorders (Thompson et al., 2009). Combined suicide with history of 
psychiatric disorders supports the notion that BDNF is a reliable growth factor reflecting suicide and stress and it is considered as a biological marker for suicide whatever the cause is (Terraciano et al., 2011; Dwivedi et al., 2012; Ambraus et al., 2016).

As regarding genetic analysis of suicide, a wide genome analysis study revealed no strong genetic association with suicide, however, mRNA biomarkers showed that BDNF expression was affected making it shadow markers for suicide in affective disorders (Pulay and Rethelyi 2016). Studies showed that committing suicide increases dramatically in psychiatric patients suffering from mental disorders including schizophrenia, bipolar or major depressive diseases, yet, the pathogenesis behind suicide in apparently normal subjects remains a mystery. It is suggested that multiple genetic interactions may be responsible for a neurodevelopmental anomaly that is responsible for suicidal attempts later on (Sokolowiski et al., 2015).

In this study, BNDF values showed higher levels in the serum of apparently healthy suicidal group in contrast to suicidal patients with psychiatric disorders whereas the blood levels of BDNF were higher than the control. These biphasic comparative results could be explained by the theory that young apparently healthy suicidal patients are under stress that promotes defensive mechanisms to overcome the pressure, and by then the secured blood levels of BDNF reflect a compensatory mechanism to stressors causing these patients to commit suicide. Finally, the defensive mechanisms are expected to be exhausted in the psychiatric suicidal group where the levels of BDNF decline. This theory is supported by recent research done on Alzheimer's patients who expressed high BDNF protein more than the control to overcome the process of degeneration (Faria et al., 2014).
A study showed that BDNF expression in an early epileptic animal model was higher in neo-cortex than the control. Later on, a chronic epileptic model revealed that BDNF expression was lower in the surrounding areas indicating plastic changes in the neurons (Liang et al., 1998). Studies suggested that high BDNF expression contributed to increased neuronal activity and associated with the development of epileptic focus despite its well-known cytoprotective function (Lindvall et al., 1994). It is difficult to conclude that suicide pathology expresses epileptic pattern despite that the epilepsy model for suicide attempt may be a new mechanism of suicide.

It is important that the locality in Mansoura, Egypt, may have a unique pattern of life style that enforces BDNF levels to increase in stressed young candidates. The rate of unemployment is very high. Such social burden induces stress on the central nervous system. A new study applied on mice showed that socially defeated wild animals expressed high levels of BDNF as a protective mechanism (Bartlang et al., 2016). From this notion it is suggested that BDNF can be a marker of prodromes of psychiatric disorders, especially if associated with suicidal events. New studies showed that high BDNF transcription is not always a sign of security. Patients with sleep disorder showed higher serum BDNF than the control (Wei et al., 2016).

Genetic linkage studies showed that the BDNF (Valine66/Met) variant is characterized by variable expression of BDNF and changes of the volume of the hippocampus (Egan et al., 2003; Chen et al., 2004; Toro et al., 2009). Both GG and AG genotypes express the same pattern of higher BDNF in apparent healthy suicide attempters. This finding postulated an epigenetic mechanism behind suicide; however, the study tracked only one SNP.

The absence of AA SNP in Egyptian samples, either suicidal or control, created a 
different signature from other racial samples. It is suggested that GG/ GA may be associated with a different biochemical response and different BDNF blood levels in reaction to stress. New studies suggest other genes interacting with BDNF in the pathogenesis of suicide including cholecystokinin (CCK) and cholecystokinin beta-receptor (CCKBR) genes (Sears et al., 2013).

The suicidal cases with history of psychiatric disorders showed lower levels of BDNF than the apparently healthy group. This decline may correlate with the development of permanent neuronal plasticity. However, both groups were still higher than the control. These results reflect modulation of neuronal plasticity in suicide victims. Wider scale study and long-term assessment of these patients are needed in both GG and GA phenotypes to reevaluate the relation between BDNF and depression with or without suicide.

It is suggested that young suicidal patients still have the reserve to overcome depression with higher blood BDNF, and the hypothesis is that repeating blood evaluation of BDNF levels would show decrease with time, especially without antidepressant treatment.

Recent studies demonstrated that the polymorphism Val66Met is associated with suicidal attempts in depressed patients using drastic methods. Another study indicated that BDNF polymorphism increased the rate of suicide in men taking antidepressants through genetic modulation of the noradrenergic system leading to suicide. Despite the suggested cyto-protective effects of antidepressants and possible elevation of BDNF, the rates of suicide increased with antidepressant medication (Akiskal and Mallya, 1987; Reeves and Brister, 2008; Schenkel et al., 2010).

\section{Conclusion}

The present study showed unexpectedly higher blood levels in the samples taken from the suicidal group. This result can be explained by compensatory mechanisms to overcome stress related to life and economic styles in the Egyptian samples. The BDNF polymorphism, Val66Met, wasn't correlated with a higher rate of suicide. All cases showed wild-type favorable genetic background. It is assumed that multiple models like genetic, epigenetic and epilepsy may be potential models for the pathogenesis of suicide. Larger samples and longer periods are needed to evaluate the relation between BDNF and suicide.

\section{Acknowledgment}

We would like to thank all members of the Immunology Unit, Clinical Pathology Department, Mansoura Faculty of Medicine, for their assistance in the lab work of this research.

\section{References}

Akiskal, H.S. and Mallya, G. (1987): "Criteria for the "soft" bipolar spectrum: Treatment implications". Psychopharmacol. Bull., 23: 68-73.

Ambrus, L.; Sunnqvist, C.; Ekman, R.; Träskman-Bendz, L. and Westrin, Å. (2016): "Plasma brain-derived neurotrophic factor and psychopathology in attempted suicide". Neuropsychology, 73(4): 241-244.

Bartlang, M.S.; Savelyev, S.A.; Johansson, A.S.; et al. (2016): "Repeated psychosocial stress at night, but not day, affects the central molecular clock". Chronobiol. Int., 31(9): 996-1007.

Brunoni, A.R.; Lopes, M. and Fregni, F. (2008): "A systematic review and meta- 
analysis of clinical studies on major depression and BDNF levels: implications for the role of neuroplasticity in depression". Int. J. Neuropsychopharmacol., 11: 11691180.

Chen, Z.Y.; Patel, P.D.; Sant, G.; et al. (2004): "Variant brain-derived neurotrophic factor (BDNF) (Met66) alters the intracellular trafficking and activity-dependent secretion of wildtype BDNF in neurosecretory cells and cortical neurons". J. Neurosci., 24: 4401-4411.

Czira, M.E.; Wersching, H.; Baune, B.T. and Berger, K. (2012): "Brainderived neurotrophic factor gene polymorphisms, neurotransmitter levels, and depressive symptoms in an elderly population". AGE, 34: 1529 1541.

Duman, R.S.; Malberg, J.; Nakagawa, S. and D'Sa, C. (2000): "Neuronal plasticity and survival in mood disorders". Biol. Psychiatry, 48: 732739.

Dwivedi, Y. (2012): Brain-derived neurotrophic factor in suicide pathophysiology. In: Dwivedi, Y., editor. The Neurobiological Basis of Suicide. Boca Raton (FL): Frontiers in Neuroscience. Chapter 8. CRC Press/Taylor \& Francis. Available from: https://www.ncbi.nlm.nih. gov/books/NBK107216/

Egan, M.F.; Kojima, M.; Callicott, J.H.; et al. (2003): "The BDNF val66met polymorphism affects activitydependent secretion of BDNF and human memory and hippocampal function". Cell, 112: 257-269.
Faria, M.C.; Gonçalves, G.S.; Rocha, N.P.; et al. (2014): "Increased plasma levels of BDNF and inflammatory markers in Alzheimer's disease". Journal Pschiatr. Res., 53: 166-172.

Fossati, P.; Radtchenko, A. and Boyer, P. (2004): "Neuroplasticity: from MRI to depressive symptoms". Eur. Neuropsychopharmacol., 14: S503-S510.

Garcia, R. (2002): "Stress, synaptic plasticity, and psychopathology". Rev. Neurosci., 13: 195-208.

Hawton, K. and van Heeringen, K. (2009): "Suicide". Lancet, 373: 1372-1381.

Liang, F.; Le, L.D. and Jones, E.G. (1998): "Reciprocal up- and down-regulation of BDNF mRNA in tetanus toxin-induced epileptic focus and inhibitory surround in cerebral cortex". Cereb. Cortex, 6: 481491.

Lindvall, O.; Kokaia, Z.; Bengzon, J.; et al. (1994): "Neurotrophins and brain insults". Trends Neurosci., 17 (11): 490496.

Piccinni, A.; Marazziti, D.; Catena, M.; et al. (2008): "Plasma and serum brain-derived neurotrophic factor (BDNF) in depressed patients during 1 year of antidepressant treatments". J. Affect Disord., 105: 279283.

Pulay, A. J. and Réthelyi, J.M. (2016): "Multimarker analysis suggests the involvement of BDNF signaling and microRNA biosynthesis in suicidal behavior". Am. J. Med. Genet. B. Neuropsychiatr. Genet., 171(6):763-766.

Reeves, R.R. and Brister, J.C. (2008): "Serious suicide attempt with duloxetine treatment" (letter). South Med. J., 701: 769.

Schenkel, L.C.; Segal, J.; Becker, J.A.; et al. (2010): "The BDNF Val66Met 
polymorphism is an independent risk factor for high lethality in suicide attempts of depressed patients". Prog. Neuropsychopharmacol.

Biol. Psychiatry, 34(6): 940-944.

Sears, C.; Wilson, J. and Fitches, A. (2013): "Investigating the role of BDNF and CCK system genes in suicidality in a familial bipolar cohort". J. Affect Disord., 151(2): 611-617.

Smith, M.A.; Makino, S.; Kvetnansky, R. and Post, R.M. (1995): "Stress and glucocorticoids affect the expression of brain-derived neurotrophic factor and neurotrophin-3 mRNAs in the hippocampus". J. Neurosci., 15: 17681777.

Sokolowski, M.; Wasserman, J. and Wasserman, D. (2016): "Polygenic associations of neurodevelopmental genes in suicide attempt". Mol. Psychiatry, 21: 1381-1390.

Terracciano, A., Lobina, M., Piras, M.G.; et al. (2011): "Neuroticism, depressive symptoms, and serum BDNF”. Psychosom. Med., 73(8): 638-642.
Thompson Ray, M.; Weickert, C.S.; Wyatt, E. and Webster, M.J. (2011): "Decreased BDNF, trkB-TK+ and $\mathrm{GAD}_{67}$ mRNA expression in the hippocampus of individuals with schizophrenia and mood disorders". J. Psychiatry Neurosci., 36 (3): 195-203.

Toro, R.; Chupin, M.; Garnero, L.; et al. (2009): "Brain volumes and Val66Met polymorphism of the BDNF gene: Local or global effects?" Brain Struct. Funct., 213: 501-509.

Van Heeringen, C.; Bijttebier, S. and Godfrin, K. (2011): "Suicidal brains: a review of functional and structural brain studies in association with suicidal behavior". Neurosci. Biobehav. Rev., 35: 688-698.

Wei, H.; Qu, H.; Wang, H.; et al. (2017): "Serum Brain-derived neurotrophic factor levels and sleep disorders in Chinese healthy and newly diagnosed type 2 diabetic population". J. Diabetes, 9 (2): 180-189.

WHO (2002): World report on violence and health. Geneva: World Health Organization. 
مستوي عامل التغذية العصبي في البلازما وتعدد أشكاله الجينية في السلوك التسممي الانتحاري

\author{
محمد عبد السميع السيل القطان ، أحمد محمد نبيل زكي هلالي ، زكريا لطفى ، عادل محمود المنصوري ، سامية أحمل حسن \\ من أقسام الطب الثرعي والسموم الإكلينيكية ـ*الباثولوجيا الإكلينيكية ـ \\ كلية الطب - جامعة المنصورة
}

يعتبر السلوك الانتحاري مشكلة صحية عامة ورئيسية، وهناك عدة عو امل تؤثنر في الاستعداد للانتحار

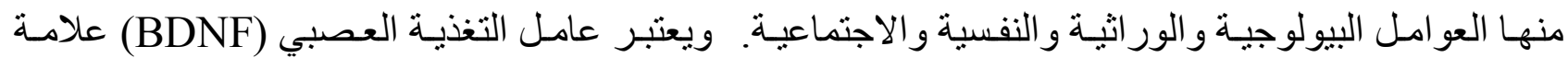

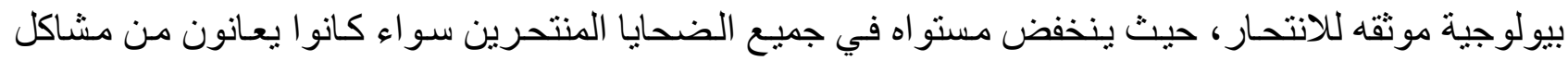

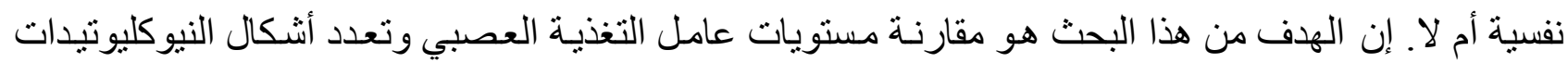

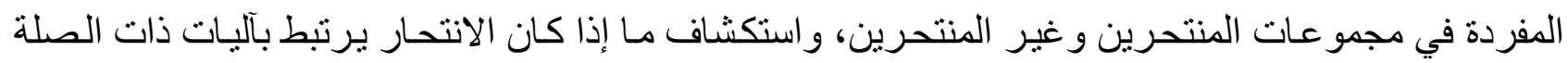

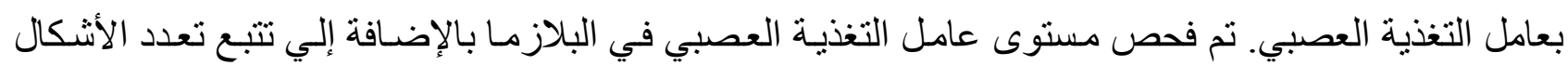

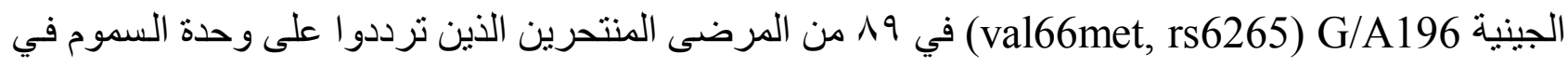

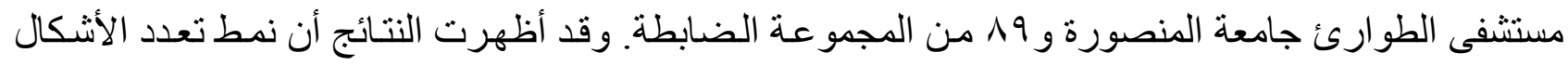

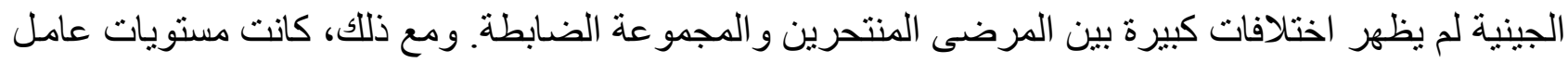
التغذية العصبي في البلازما أعلى في حالات الانتحار. 